\title{
Concurrent Validity of the MOX Activity Monitor Compared to the ActiGraph GT3X
}

Citation for published version (APA):

van der Weegen, S., Essers, H., Spreeuwenberg, M., Verwey, R., Tange, H., de Witte, L., \& Meijer, K. (2015). Concurrent Validity of the MOX Activity Monitor Compared to the ActiGraph GT3X. Telemedicine and E-health, 21(4), 259-266. https://doi.org/10.1089/tmj.2014.0097

Document status and date:

Published: 01/04/2015

DOI:

10.1089/tmj.2014.0097

Document Version:

Publisher's PDF, also known as Version of record

Document license:

Taverne

\section{Please check the document version of this publication:}

- A submitted manuscript is the version of the article upon submission and before peer-review. There can be important differences between the submitted version and the official published version of record.

People interested in the research are advised to contact the author for the final version of the publication, or visit the DOI to the publisher's website.

- The final author version and the galley proof are versions of the publication after peer review.

- The final published version features the final layout of the paper including the volume, issue and page numbers.

Link to publication

\footnotetext{
General rights rights.

- You may freely distribute the URL identifying the publication in the public portal. please follow below link for the End User Agreement:

www.umlib.nl/taverne-license

Take down policy

If you believe that this document breaches copyright please contact us at:

repository@maastrichtuniversity.nl

providing details and we will investigate your claim.
}

Copyright and moral rights for the publications made accessible in the public portal are retained by the authors and/or other copyright owners and it is a condition of accessing publications that users recognise and abide by the legal requirements associated with these

- Users may download and print one copy of any publication from the public portal for the purpose of private study or research.

- You may not further distribute the material or use it for any profit-making activity or commercial gain

If the publication is distributed under the terms of Article $25 \mathrm{fa}$ of the Dutch Copyright Act, indicated by the "Taverne" license above, 


\section{Concurrent Validity of the MOX Activity Monitor Compared to the ActiGraph GT3X}

\author{
Sanne van der Weegen, MSc, ${ }^{1}$ Hans Essers, MSc, ${ }^{2}$ \\ Marieke Spreeuwenberg, PhD, ${ }^{1}$ Renée Verwey, RN, MSc, ${ }^{1,3}$ \\ Huibert Tange, MD, PhD, ${ }^{1}$ Luc de Witte, MD, PhD, ${ }^{1,3}$ \\ and Kenneth Meijer, $P h D^{2}$ \\ ${ }^{1}$ CAPHRI School for Public Health and Primary Care and \\ ${ }^{2}$ NUTRIM School for Nutrition, Toxicology and Metabolism, \\ Maastricht University, Maastricht, The Netherlands. \\ ${ }^{3}$ Research Centre Technology in Care, Zuyd University \\ of Applied Sciences, Heerlen, The Netherlands.
}

\begin{abstract}
Background: The It's LiFe! monitoring and feedback tool embedded in primary care practice is promising in helping people to achieve an active lifestyle. This new tool consists of an activity monitor (the MOX), which is connected to a smartphone application and to a Web service for patients and care providers. The aim of this study was to develop thresholds for the moderate and vigorous activity categories and examine the concurrent validity of the MOX in relation to the ActiGraph (Pensacola, FL) GT3X in healthy participants and chronically ill patients (chronic obstructive pulmonary disease and type 2 diabetes) in a laboratory situation and during daily living. Materials and Methods: Participants wore the two activity monitors simultaneously on the lower back. An incremental treadmill protocol was executed by 8 healthy adults and 10 patients. For daily living measurements, 15 healthy adults and 12 patients wore the devices for 6-7 days. Daily living data were corrected for non-wear time, using diary information. Results: On the treadmill there was an excellent correlation between the ActiGraph and MOX counts (mean $\mathrm{r}=0.99$ in healthy participants and mean $\mathrm{r}=0.98$ in patients). Correlation during daily living was moderate (mean $\mathrm{r}=0.72$ ) in healthy adults and good (mean $\mathrm{r}=0.82$ ) in patients. BlandAltman plots showed no perfect agreement between the two devices in minutes per category. However, a histogram of misclassified minutes showed that misclassification occurred around category thresholds. Conclusions: The MOX is capable of measuring physical activity and can be used in the It's LiFe! intervention.
\end{abstract}

Key words: accelerometry, e-health, motor activity, pulmonary disease, diabetes mellitus

\section{Introduction}

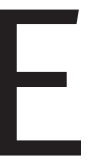

ngagement in regular physical activity is effective in the primary and secondary prevention of several chronic diseases (e.g., cardiovascular disease, diabetes, and some cancers) and reduces the risk of premature death. ${ }^{1,2}$ Globally, however, 31\% of the people above 15 years old are insufficiently active. $^{3}$ Therefore numerous physical activity-promoting interventions have been developed. The most successful behavioral interventions include a mix of behavior change techniques, such as goal setting, barrier identification, action planning, social support, selfmonitoring of behavior, revising of behavioral goals, and giving advice and providing written materials. ${ }^{4-6}$ Technology can help to ease the implementation of behavior change techniques in daily practice and can support healthcare professionals in their coaching role. For example, pedometers in physical activity interventions, when used for self-monitoring, seem to increase the daily steps significantly, especially when combined with goal setting. ${ }^{7}$ However, the ability of pedometers to assess free-living activity is limited because they cannot measure the frequency, duration, and intensity of physical activity. ${ }^{8}$ Accelerometers do have these possibilities.

In the newly developed It's LiFe! intervention, ${ }^{9-12}$ a monitoring and feedback tool embedded in a behavior change counseling protocol supports patients in achieving an active lifestyle and gives care providers the possibility of using objective activity results while coaching. The purpose of the intervention is to support participants to increase the time spent in the moderate and vigorous activity category and diminish the time spent in the sedentary category. The It's LiFe! tool (Fig. 1) consists of an accelerometer (MOX), which is connected to a smartphone with Bluetooth ${ }^{\circledR}$ (Bluetooth SIG, Kirkland, WA). On both the smartphone and on a Web site users can see their minutes of activity in the moderate and vigorous category compared with their personal goal in minutes per day and receive feedback messages and behavioral change dialogue sessions. All feedback messages are in a positive tone and are based on personal goal achievement. Dialogue sessions make participants aware of the physical activities they prefer and barriers to overcome and guide them in activity planning and searching for social support. What makes the It's LiFe! tool unique is that it is developed in a usercentered design process together with patients and care providers ${ }^{9}$ and that the activity results and answers to dialogue sessions are automatically sent to the care provider. The care provider uses the information to set an appropriate activity goal together with the patient, which reinforces awareness, motivation, and support for the behavior change. Currently this coaching role is executed by a practice nurse in primary care.

To make use of the full potential of the user-centered design approach, it was necessary that all features of the tool were adaptable. Therefore a new activity monitor (the MOX) was developed that allowed adaptation of the algorithm to the preferences of the end users and that could communicate with other systems. 


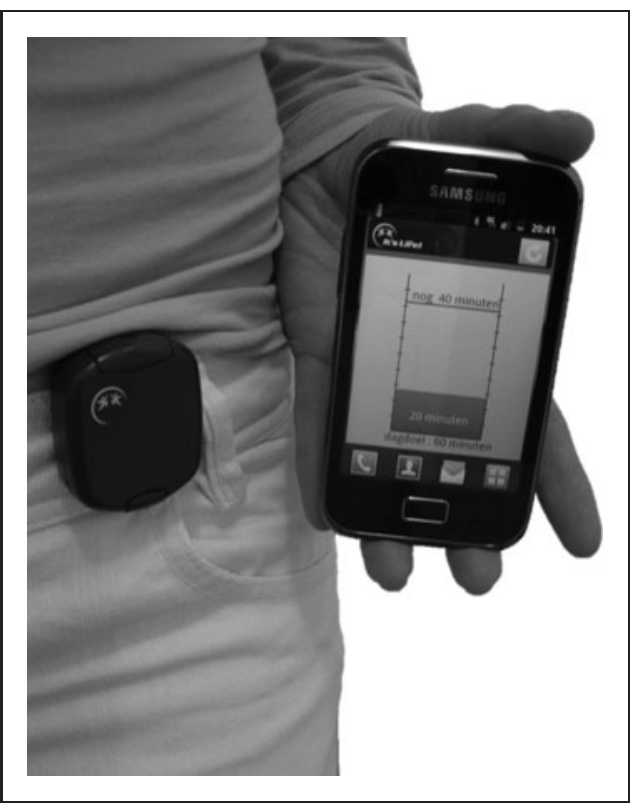

Fig. 1. The It's LiFe! monitoring and feedback tool. The MOX and the real-time feedback (activity results in minutes a day compared with a personal goal) on the smartphone application are shown.

For an effective intervention with sufficient adherence from users, it is necessary that the tool provides accurate activity results. Methods to validate accelerometers include the following: against doubly labeled water (DLW), ${ }^{8}$ (video) observation, indirect calorimetry, or another accurate accelerometer. DLW is expensive and merely gives information about energy expenditure rather than the distribution of activity bouts over time, and indirect calorimetry and video observation are only suitable in a laboratory setting. Therefore, we chose to evaluate the MOX in relation to another accelerometer, the ActiGraph (Pensacola, FL) GT3X. The ActiGraph GT3X is one of the most widely used and validated activity monitors in researcher environments ${ }^{13-15}$ and correlates as one of the best with indirect calorimetry $(r=0.77)^{16}$ and DLW $(r=0.68) .{ }^{17}$

The goal of the current study was twofold. First, thresholds for different activity intensities for the MOX were determined. Second, the It's LiFe! activity monitor, the MOX, was validated against the ActiGraph GT3X. This was tested on a treadmill and in daily life. This research was conducted in both healthy adults and in different patient populations because activity monitor output can differ between populations, owing to a difference in walking patterns. ${ }^{18}$

\section{Materials and Methods STUDY DESIGN}

The following methods were used for the multiple purposes of this study.

Thresholds of the MOX were defined for different intensity levels (moderate and vigorous) by analyzing the data of five healthy participants who wore the MOX and the ActiGraph simultaneously during daily living. Thresholds for these categories were defined because feedback of the tool is aimed at these categories.

The concurrent validity of the two monitors was defined, and the thresholds of the MOX were validated by the data of an incremental treadmill protocol by 8 healthy adults and 10 participants with chronic obstructive pulmonary disease (COPD) or type 2 diabetes and data of a second group of 10 healthy participants and 12 people with COPD or type 2 diabetes during daily living.

\section{PARTICIPANTS}

Twenty-two healthy volunteers (18-70 years of age) were recruited from the researchers' local networks by an invitation letter. Thirteen volunteers with COPD or type 2 diabetes (40 years or older), who were able to walk independently, were recruited by patient representatives from the national patient associations and by a practice nurse through an invitation letter. One healthy participant and 9 patients contributed to both the measurements on the treadmill and during daily living. Written informed consent was obtained from all participants before study initiation. Confidential processing of data and anonymity were guaranteed. Participants had the opportunity to withdraw from the study at any time. The Medical Ethical Committee of MUMC + approved this study (protocol number 11-4-120).

\section{ACTIVITY MONITORS}

The MOX (model MMOXX1.01) is an activity monitor (4.5× $4.0 \times 1.4 \mathrm{~cm}$ ) with a sample frequency of $25 \mathrm{~Hz}$. The MOX measures, in three axes, the acceleration data $( \pm 6 \mathrm{G})$. The data are filtered with a Butterworth $0.1-\mathrm{Hz}$ 4th-order high-pass filter. These data are converted to activity counts via embedded software by integrating the acceleration over 1-min episodes and summing this outcome for all three axes. Subsequently the data are calibrated so that a constant acceleration of $1 \mathrm{G}$ over $1 \mathrm{~min}$ corresponds to 1,000 counts. ${ }^{19}$ The ActiGraph GT3X is a three-axis activity monitor $(3.8 \times 3.7 \times 1.8 \mathrm{~cm})$ with a sample frequency of $30 \mathrm{~Hz}$, which provides activity data in a scale from 0 to 15,000 counts/min. In both devices the counts were recorded in the internal memory housed in the monitor and transferred to a computer with a micro-USB. For the ActiGraph, the program ActiLife version 5.10.0 was used, whereas for the MOX, MOXBWO software was used. In the It's LiFe! intervention the MOX will transfer its data automatically with Bluetooth to a smartphone.

\section{DATA COLLECTION PROCEDURES}

Throughout testing, the two activity monitors were worn simultaneously next to each other with an elastic belt tightly secured at the lower back. The devices were synchronized with the time on the same computer, and batteries were charged by the researchers before distribution, as the devices were able to monitor for 8 days. People with type 2 diabetes were asked to report their last measured glycosylated hemoglobin value, and people with COPD were asked to report their last spirometry results.

Treadmill. All participants wore normal clothes (with a restriction of high heels) with the MOX and the ActiGraph on their lower back. 


\section{VALIDATION OF THE MOX, THE IT'S LIFE! ACTIVITY MONITOR}

For the healthy participants, the treadmill started at $3 \mathrm{~km} / \mathrm{h}$ (1.9 mph) and became faster every minute by $1 \mathrm{~km} / \mathrm{h}(0.6 \mathrm{mph})$ until the participant indicated he or she wanted to stop. Maximum speed was $11 \mathrm{~km} / \mathrm{h}(6.8 \mathrm{mph})$. The participants with a chronic disease started at a pace of $2 \mathrm{~km} / \mathrm{h}(1.2 \mathrm{mph})$. The treadmill speed was increased every $3 \mathrm{~min}$ by $0.5 \mathrm{~km} / \mathrm{h}(0.3 \mathrm{mph})$ until the patients indicated they wanted to stop, to prevent overexertion.

Monitoring of activities during daily living. The activity pattern during daily life was measured for 6-7 consecutive days during waking hours, except for showering, swimming, or other water activities. The participants were asked to undertake their normal daily activities and to keep a diary to report at what time they wore the devices.

\section{STATISTICAL ANALYSIS}

All analyses were performed using IBM (Armonk, NY) Statistical Product and Service Solutions (SPSS version 20.0). Graphs were conducted in Microsoft (Redmond, WA) Excel ${ }^{\mathrm{TM}}$ 2010. Bland-Altman plots were done with MedCalc ${ }^{\circledR}$ version 12.5.0.0 software (MedCalc Software, Ostend, Belgium).

Define thresholds. Thresholds for moderate- and vigorous-intensity activities have been defined for the ActiGraph ${ }^{14}$ : moderate, 2,6906,166 counts (3.0-6.0 metabolic equivalents of task [METs]); and vigorous, $\geq 6,167$ counts ( $>6.0$ METs). The activity categories of the ActiGraph were used as a standard to define the thresholds for the activity categories of the MOX. To this end, agreement of allocating activities to either of these categories for the two devices was tested by making small incremental steps in the MOX thresholds (i.e., 10 MOX counts) until the smallest absolute difference was obtained between minutes spent per category between the two devices.

Concurrent validity. For the treadmill measurements Pearson correlation per person was calculated between speed and MOX counts per minute and between ActiGraph and MOX counts per minute. To account for the dependency of measurements of speed within participants, the associations between MOX counts and speed (dependent variable) and between MOX counts and ActiGraph counts per minute (dependent variable) were analyzed using multilevel, linear, mixed model analyses with speed at level 1 and participant at level 2 factors. Akaike's information criterion was used to choose the best model. For daily living measurements the Spearman correlation was calculated between the counts per minute of the Actigraph and the MOX per person per day. Values over 0.8 were rated as good. To prevent an inflated high correlation between the devices due to non-wear time during daily life measurements, periods of non-wear time were omitted based on diary information from the participants. Agreement between minutes per category (moderate- and vigorous-intensity activities) measured by the different devices was analyzed using Bland-Altman plots for repeated measures. The mean values and difference with the ActiGraph were plotted, and the systematic bias and limits of agreement (within mean \pm 2 standard deviation [SD] of the mean differences) were obtained. To gain further insight into misclassified minutes, histograms of the counts of these minutes were obtained.

\section{Results \\ PARTICIPANTS' CHARACTERISTICS THRESHOLD DEFINITION}

The first group of five healthy participants had a mean age of $33.4 \pm 11.6$ years. The mean height and weight were $181.0 \pm 10.1 \mathrm{~cm}$ and $75.7 \pm 12.3 \mathrm{~kg}$, respectively. The participants wore the devices on $6.8 \pm 0.8$ days.

\section{PARTICIPANTS' CHARACTERISTICS VALIDATION}

Participants' characteristics are presented in Table 1.

Treadmill. Eight healthy participants, five people with COPD, and five people with diabetes type 2 walked on the treadmill. The data of 1 patient with COPD could not be used because this person was not able to walk on the treadmill for $3 \mathrm{~min}$ without resting.

Daily living. The 10 healthy participants spent on average 26.1 (SD 18.0) $\mathrm{min}$ in the moderate category and 4.4 (SD 13.2) $\mathrm{min}$ in the vigorous category, as determined by the ActiGraph. Out of 67 days, the ActiGraph did not record data on 7 days, and on 2 days the battery of the MOX was empty. Among the participants with a chronic disease,

\begin{tabular}{|c|c|c|}
\hline & HEALTHY & PATIENTS \\
\hline Treadmill $(n)$ & 8 & 9 \\
\hline Age (years) & $24.1(5.3)$ & $60.9(7.1)$ \\
\hline COPD/DM2 (n) & - & $4 / 5$ \\
\hline Height $(\mathrm{cm})$ & $183.3(9.4)$ & $170.9(11.4)$ \\
\hline Weight (kg) & $75.1(13.4)$ & $92.4(27.0)$ \\
\hline BMI $\left(\mathrm{kg} / \mathrm{m}^{2}\right)$ & $22.2(2.5)$ & $31.3(7.5)$ \\
\hline FEV1 (\% predicted) & - & $52.5(16.6)(n=4)$ \\
\hline $\mathrm{HbA} 1 \mathrm{c}(\mathrm{mmol} / \mathrm{mol})$ & - & $52.2(6.0)(n=5)$ \\
\hline Daily living $(n)$ & 10 & 12 \\
\hline Age (years) & $30.4(8.3)$ & $61.6(9.2)$ \\
\hline COPD/DM2 (n) & - & $5 / 7$ \\
\hline Height $(\mathrm{cm})$ & 175 (9.6) & $168.6(9.9)$ \\
\hline Weight (kg) & $68.1(8.9)(n=9)$ & 95.6 (31.5) \\
\hline BMI $\left(\mathrm{kg} / \mathrm{m}^{2}\right)$ & $22.7(2.8)$ & 33.3 (9.8) \\
\hline Valid wear days & $5.8(1.2)$ & $6.3(1.4)$ \\
\hline Wear time (min/day) & 746.4 (191.3) & $854.0(174.6)$ \\
\hline FEV1 (\% predicted) & - & $50.5(12.6)(n=4)$ \\
\hline $\mathrm{HbA1c}(\mathrm{mmol} / \mathrm{mol})$ & - & $53.1(6.4)(n=7)$ \\
\hline
\end{tabular}

$\mathrm{BMI}$, body mass index; COPD, chronic obstructive pulmonary disease; DM2, diabetes mellitus type 2; FEV1, forced expiratory volume in $1 \mathrm{~s}$; HbA1c, glycosylated hemoglobin. 


\section{VAN DER WEEGEN ET AL.}

five participants had type 2 diabetes, and seven suffered from COPD. Patients were active for 11.6 (SD 13.1) $\mathrm{min}$ in the moderate category and 0.7 (SD 3.9) $\mathrm{min}$ in the vigorous category. In chronic disease patients the ActiGraph did not record data on 14 out of 89 days.

\section{DEFINE THRESHOLDS}

The best possible agreement between the activity classification of the ActiGraph and the MOX was reached with the following thresholds for the MOX: moderate, 400860 counts/min; vigorous, $860-\infty$ counts/min. These thresholds were used to define the minutes of activity in the different intensity levels during the daily living of the patients.

\section{CONCURRENT VALIDITY}

Treadmill. MOX activity counts per minute increased with the intensity of walking in healthy participants (mean $r=0.98$; range, 0.96-0.99) and in patients (mean $r=0.99$; range, 0.98-1). Linear mixed model analyses showed that MOX counts significantly increased with speed in healthy participants and in patients (both $p<0.00$ ) (Figs. 2 and 3). Pearson correlation between the ActiGraph and the MOX counts per minute was good. In healthy participants mean $r$ was 0.99 (range, 0.981.00). In chronic disease patients, mean $r$ was 0.98 (range, 0.951.00). Linear mixed model analyses showed that in healthy participants and in chronic disease patients, MOX counts significantly increased with ActiGraph counts (in both groups, $p<0.00$ ). Figures 2 and 3 show that the threshold for moderate-intensity activities lies between 3 and $4 \mathrm{~km} / \mathrm{h}$ and that the variance in counts increases with speed. The increase in variance with speed is also observed in ActiGraph counts.

Daily living. Spearman correlation per day per participant between MOX and ActiGraph counts during daily living was for

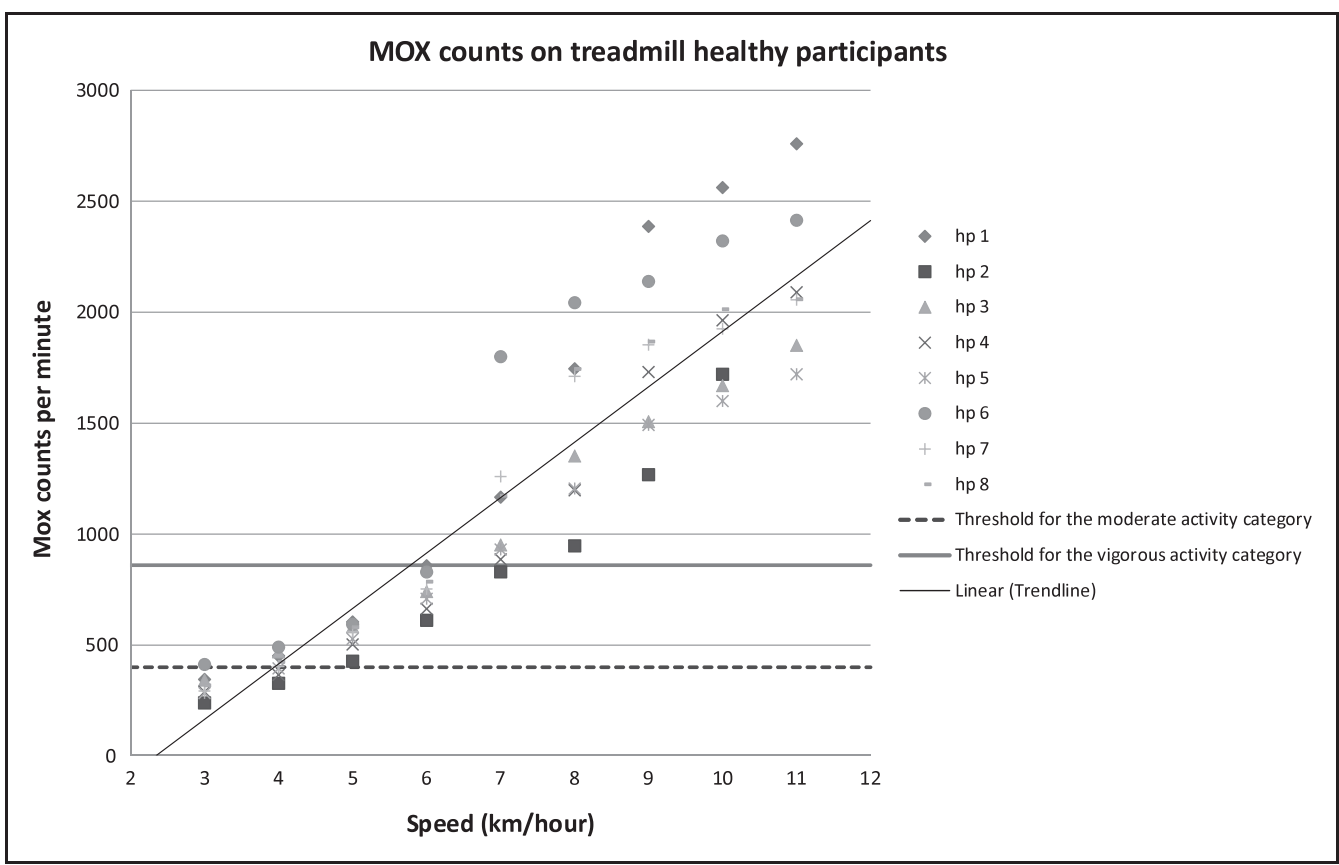

Fig. 2. Activity counts per minute of the MOX in healthy participants (hp) during treadmill walking. healthy participants on average $r=0.72$ (range, 0.18-0.96) and in patients $r=0.82$ (range, 0.60-0.94).

In healthy participants, Bland-Altman plots (Figs. 4 and 5) showed a mean difference of $9.1 \mathrm{~min}$ in the moderate category and $1.8 \mathrm{~min}$ in the vigorous category. The 95\% limits of agreement were wide: -37.0

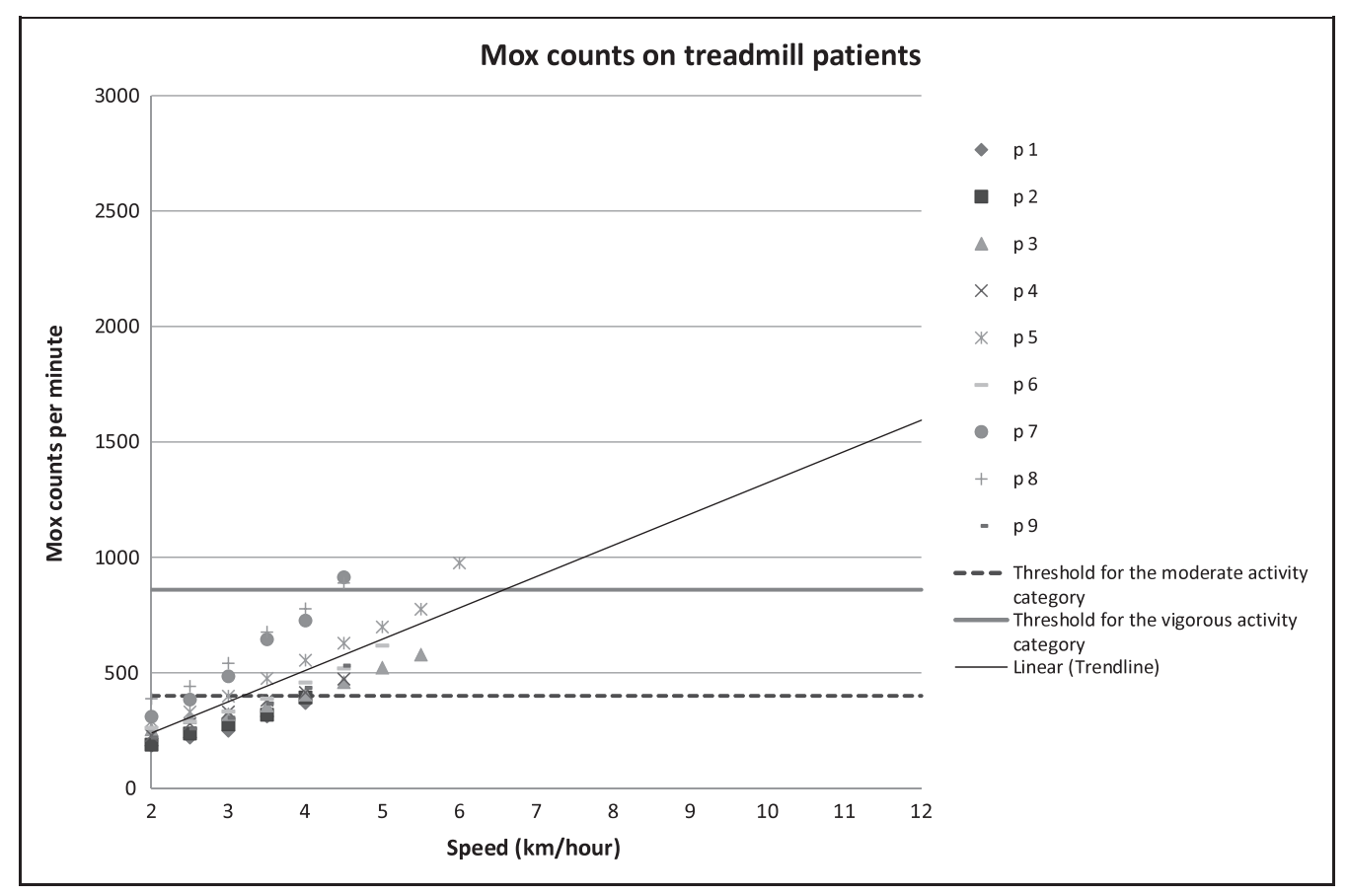

Fig. 3. Activity counts per minute of the MOX in chronic disease patients (p) during treadmill walking. 


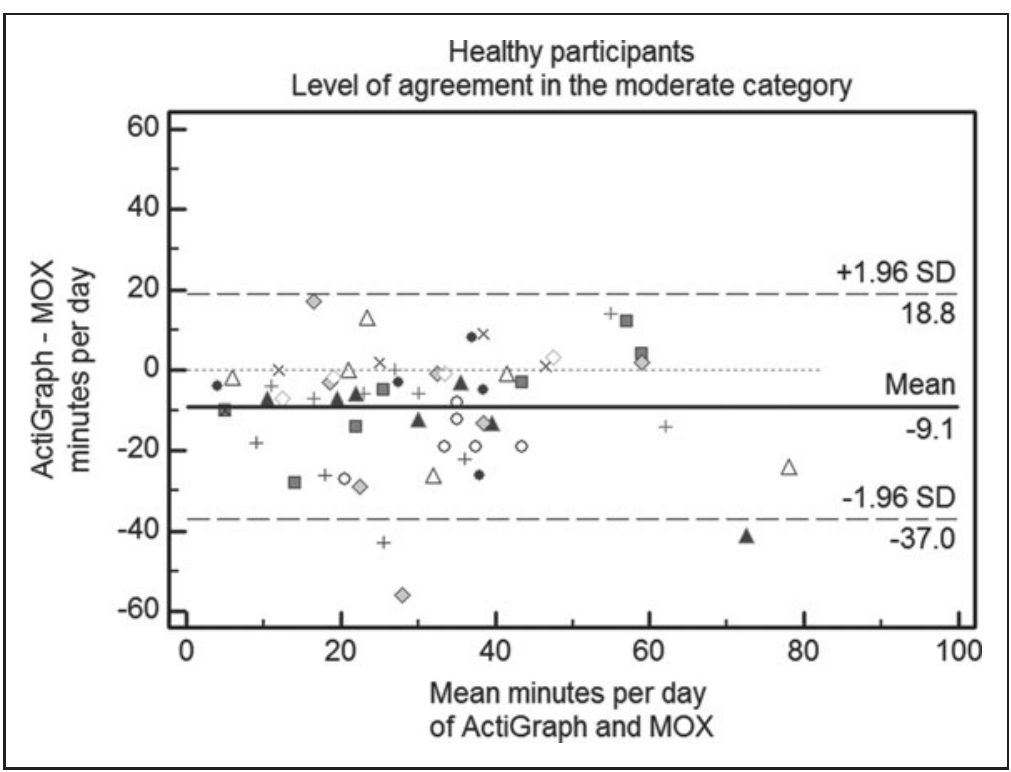

Fig. 4. Determination of agreement between the ActiGraph accelerometer and MOX in minutes in the moderate-intensity category for healthy participants by Bland-Altman plots for repeated measures. The solid line represents the mean difference between the devices; the dashed lines represent the limits of agreement. SD, standard deviation.

to $18.8 \mathrm{~min}$ in the moderate category and -10.6 to $7.1 \mathrm{~min}$ in the vigorous category.

In the chronic disease patient group, Bland-Altman plots (Figs. 6 and 7) showed a mean difference of $2.3 \mathrm{~min} /$ day in the moderate category between the MOX and the ActiGraph. The limits of

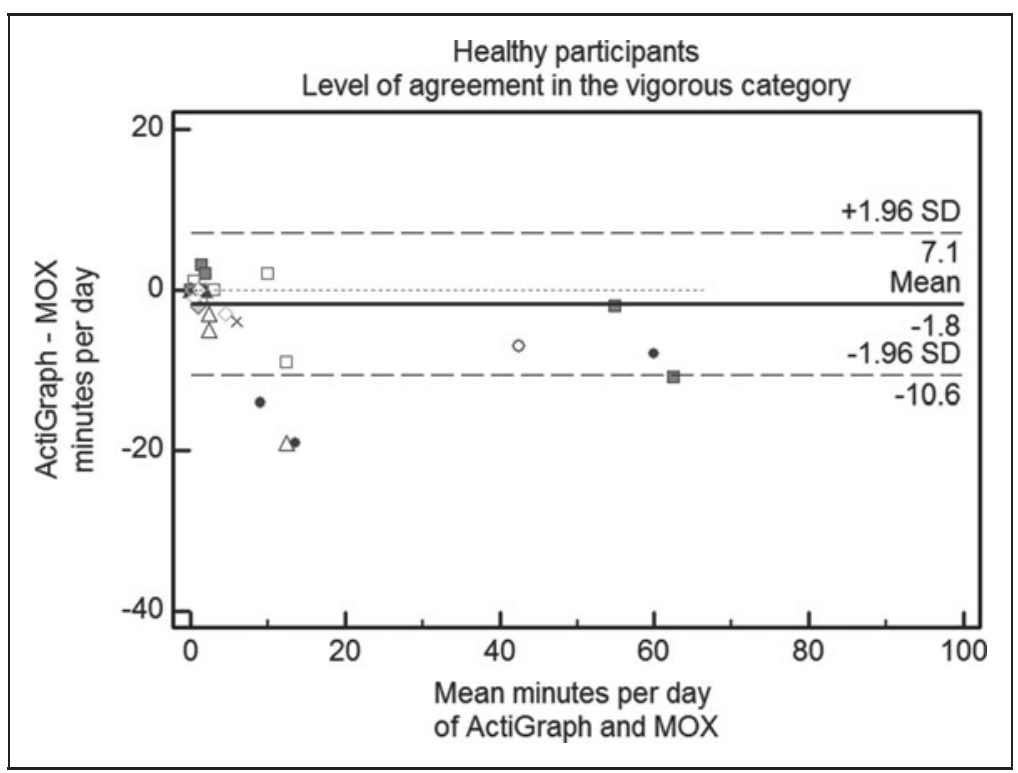

Fig. 5. Determination of agreement between the ActiGraph accelerometer and MOX in minutes in the vigorous-intensity category for healthy participants by Bland-Altman plots for repeated measures. The solid line represents the mean difference between the devices; the dashed lines represent the limits of agreement. SD, standard deviation. agreement were from -27.6 to $22.9 \mathrm{~min}$. In the vigorous category limits of agreement ranged from -9.5 to $8.5 \mathrm{~min}$ (mean difference, $0.5 \mathrm{~min}$ ). Within participants there is a consistent over- or underestimation of minutes per category.

In healthy participants the MOX placed 3.6\% of the total minutes in a different category, compared with the ActiGraph; in chronic disease patients this value was 1.5\%. Histograms of counts of the dissimilar classified minutes (Figs. 8 and 9) showed that misclassification occurred especially around category thresholds.

\section{Discussion}

In this study thresholds for moderate- and vigorousintensity physical activity were defined for the MOX (the activity monitor embedded in the It's LiFe! tool), and the activity results from the MOX were compared with the activity results from the ActiGraph GT3X to assess concurrent validity.

MOX activity counts per minute did significantly increase with speed and had an excellent correlation with the reference activity monitor, the ActiGraph GT3X, on the treadmill (mean $r=0.99$ and 0.98 , respectively) and a moderate to good correlation in daily living (mean $r=0.72$ and 0.82 , respectively). Bland-Altman plots showed that during daily living there was no perfect agreement between the number of minutes the MOX and the ActiGraph placed in the moderate- and vigorousintensity activity categories. Sometimes, the MOX overestimated activity compared with the ActiGraph, and sometimes the MOX underestimated activity, with an average overestimation in both categories. In total, the MOX misclassified 3.6\% of the total analyzed minutes of healthy participants and 1.5\% of the minutes for chronic disease patients. With the chosen design it is not known, however, whether the ActiGraph or the MOX is responsible for the misclassification. The ActiGraph GT3X does not have a perfect correlation $(r=0.68)$ with measures of energy expenditure, DLW, ${ }^{17}$ or indirect calorimetry $(r=0.77) .{ }^{16}$ In addition, in this study the ActiGraph did not work on 21 days out of 156 days (these days were excluded from the analyses), and sometimes there were suspicious data (i.e., long periods of zero ActiGraph counts were observed on 7 days [included in the analyses]). A check of the analyses without these days resulted in minimal changes. Most important, however, was that misclassification did occur around category thresholds, which shows that misclassification is inevitable with the choice of hard thresholds.

A potential alternative for hard thresholds is "fuzzy logic sets." With the fuzzy logic classifier a count will not be classified in one activity category, but it will represent how much it corresponds to each category. At that moment ifthen rules will be applied to classify the count to an activity category. ${ }^{20}$ 


\section{VAN DER WEEGEN ET AL.}

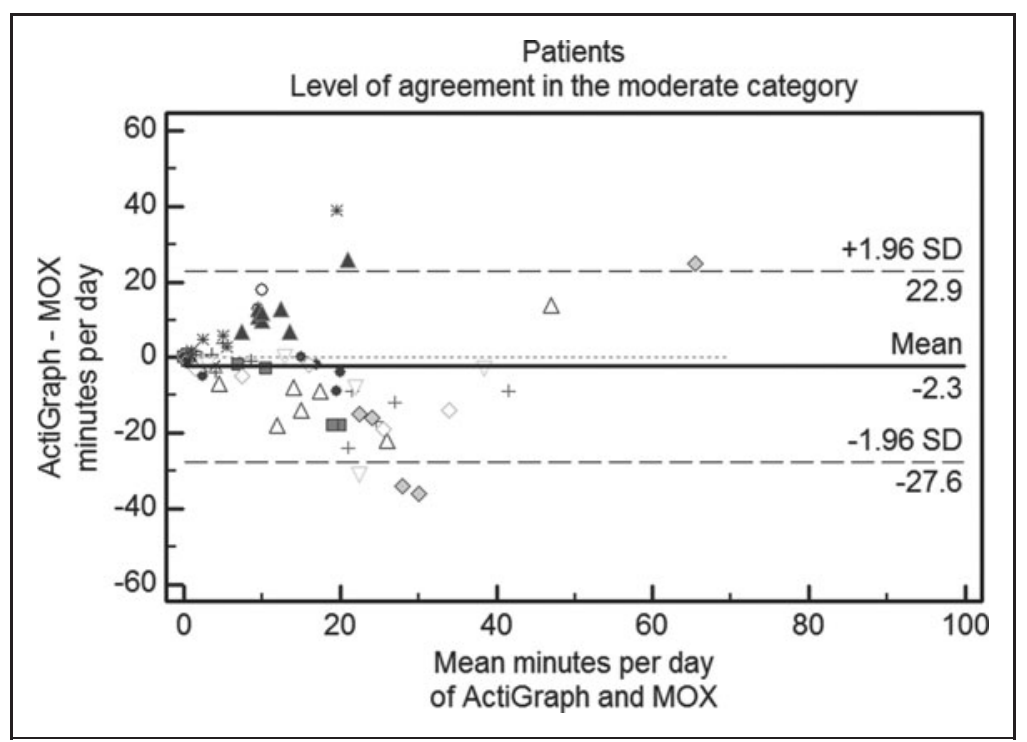

Fig. 6. Determination of agreement between the ActiGraph accelerometer and MOX in minutes in the moderate-intensity category for chronic disease patients by Bland-Altman plots for repeated measures. The solid blue line represents the mean difference between the devices; the dashed lines represent the limits of agreement. SD, standard deviation.

Another issue with hard thresholds is that at-the-same-speed counts differ between participants, and variance between participants increased with speed. Therefore there is a difference in the prediction equation if running is included (in healthy participants). Another study also proved that the slope of prediction equations

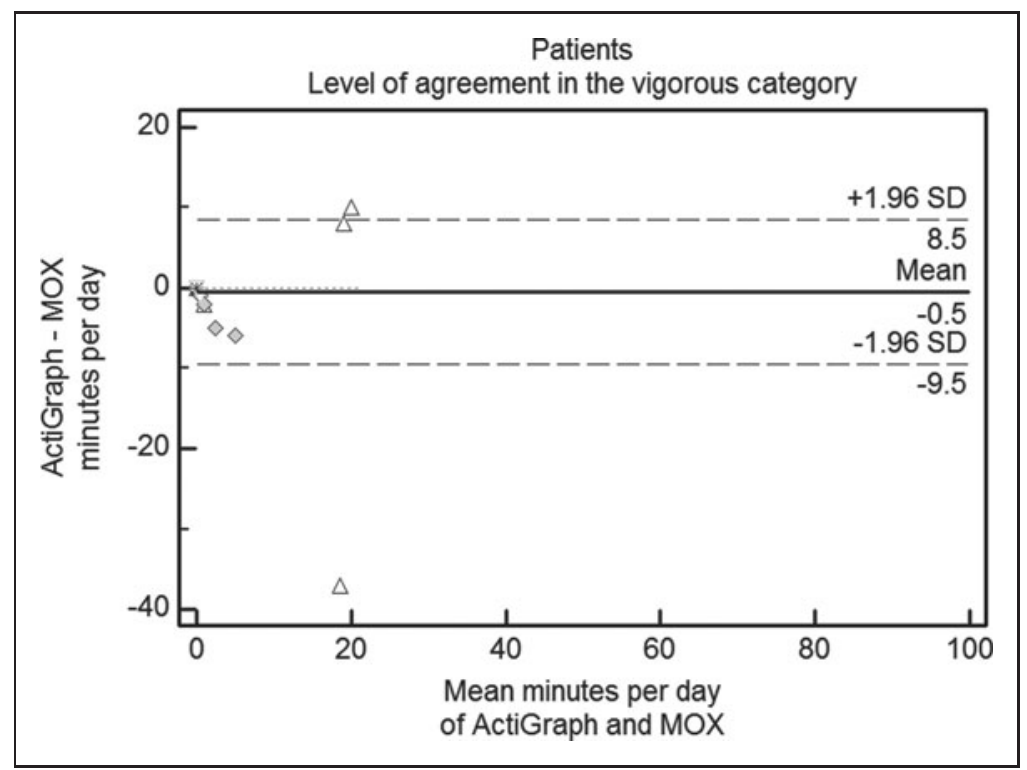

Fig. 7. Determination of agreement between the ActiGraph accelerometer and MOX in minutes in the vigorous-intensity category for chronic disease patients by Bland-Altman plots for repeated measures. The solid blue line represents the mean difference between the devices; the dashed lines represent the limits of agreement. SD, standard deviation. differs among different activities. ${ }^{21}$ Also, in other studies the variance of the counts increased with speed, ${ }^{22-24}$ and even the variance in volume of $\mathrm{O}_{2}$ (in $\mathrm{mL} / \mathrm{kg} / \mathrm{min}$ ) increased with speed. $^{25,26}$ However, within participants MOX counts increased consistently, and during daily life there was a merely consistent over- or underestimation of activity per participant. The difference in counts per participant could be caused by a different walking pattern, body composition, or a slightly different placement of the device. For instance, a small person with a higher step frequency than a taller person will collect more counts per minute. Therefore it is hard to set one threshold for all users. For an equation to calculate personal thresholds at 3 METs, based on weight, height, and age, the MOX should be validated with DLW or indirect calorimetry.

However, a different threshold per user is undesirable in daily practice and does not guarantee a perfect fit between threshold and user. In a recent study by Santos-Lozano et al., ${ }^{27}$ new equations were formulated to predict energy expenditure from activity counts, age, body mass, and gender in different age groups. With the new equations, more accurate thresholds were defined. Yet, significant differences between energy expenditure calculated from the equations and indirect calorimetry were still observed at certain speeds. In daily living differences between energy expenditure measured by accelerometer output and indirect calorimetry will be even higher because accelerometers worn on the hip are mostly sensitive to gait-related activities and not for activities involving upper-extremity movement or seated activities. ${ }^{28}$ Furthermore, people with chronic disorders like COPD have a poor mechanical efficiency compared with healthy people, ${ }^{29}$ which means that a threshold set at 3 METs for the general population is not achievable for people with COPD. Consequently results of the It's LiFe! tool will not be a perfect representation of an individual's physical activity. In a previous study, ${ }^{30}$ accelerometer output resulted in a $16.4 \%$ difference with direct observation of energy expenditure. Future research could refine MOX thresholds, with a validation study with indirect calorimetry. Also, the thresholds in this study were defined while the MOX and the ActiGraph were placed on the lower back, when in reality they will be worn on the hip, and ActiGraph thresholds were defined for wearing on the hip.

In the It's LiFe! Intervention, the uncertainties caused by the rigid thresholds are solved by a premeasurement period. Participants of the intervention use the tool for 2 weeks, and after this interval they set a personal goal in collaboration with their care provider. Thus individual factors that influence activity outcome are taken into account, and personal progress is measured after goal setting. Furthermore, care providers are instructed to lower the threshold (270 counts/ $\min$ for $\pm 2 \mathrm{~km} / \mathrm{h}, 363$ counts $/$ min for $\pm 3 \mathrm{~km} / \mathrm{h}$ ) in case the premeasurement reveals that a participant is unable to 


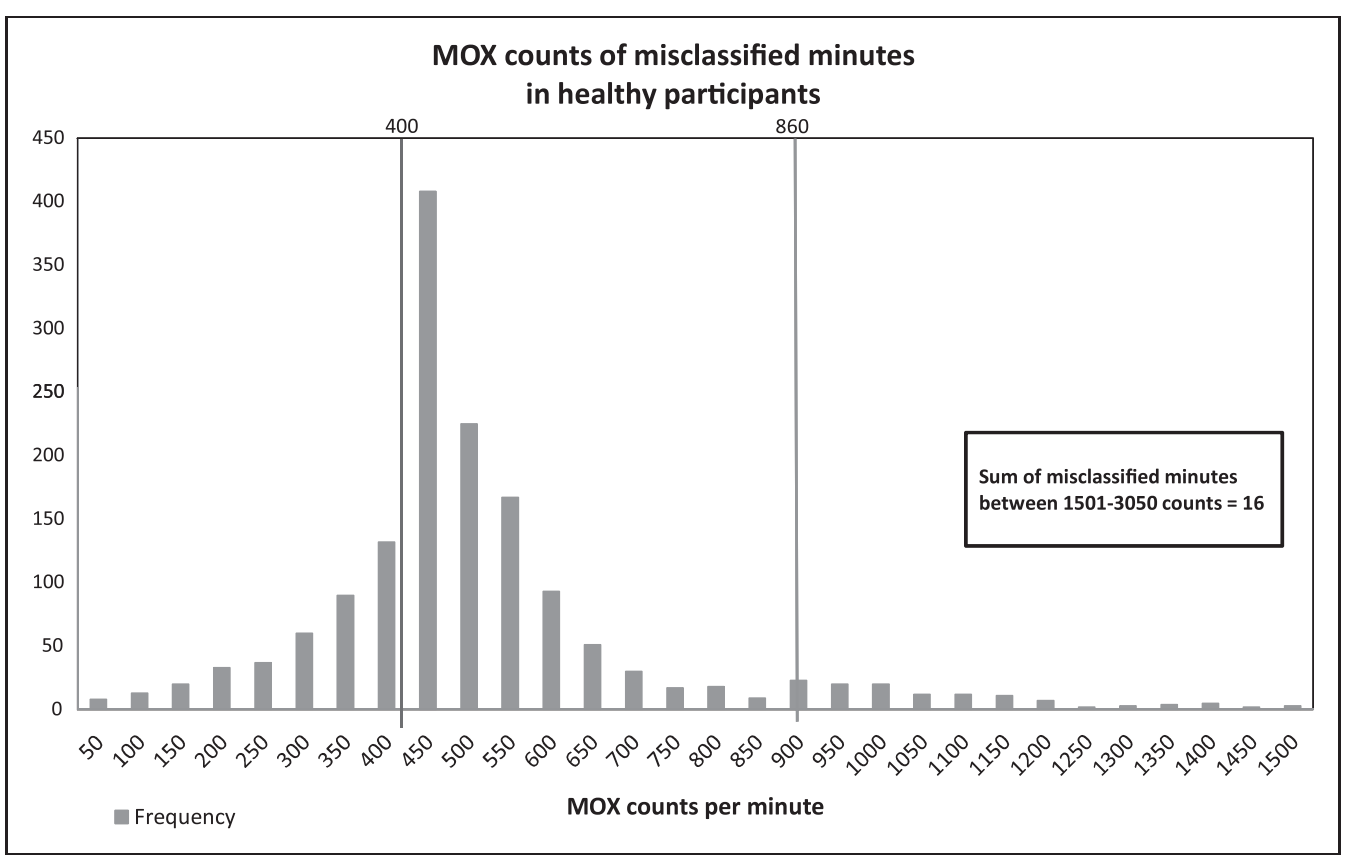

Fig. 8. Histogram of counts of misclassified minutes in healthy participants.

exceed the general threshold while walking. This does not overcome the fact that non-gait-related activities will be underestimated. Therefore the participants have the opportunity to write down remarks in the system to notate extra activities.

In conclusion, the MOX is able to assess differences in activity intensity and classify free-living physical activity behavior in min-

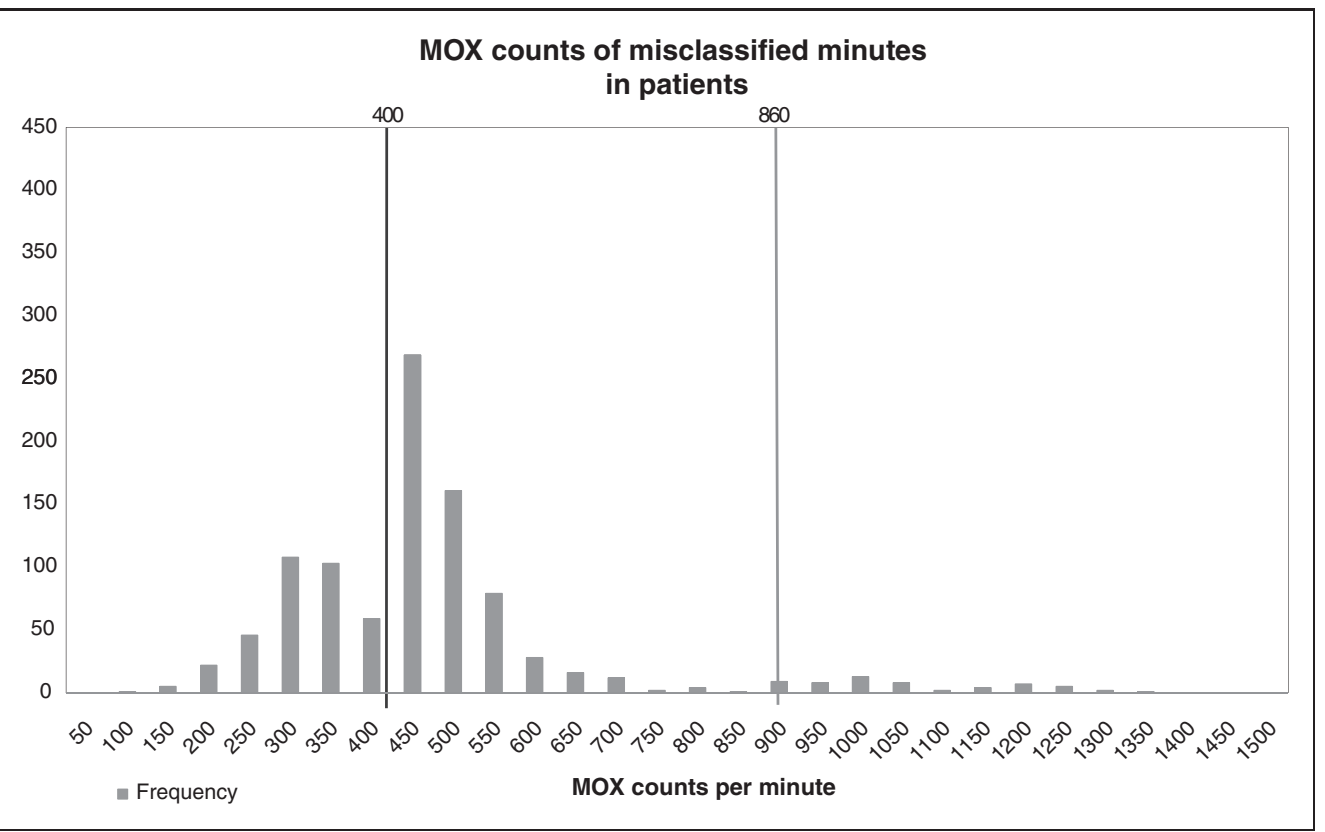

Fig. 9. Histogram of counts of misclassified minutes in chronic disease patients. utes and can be used in the It's LiFe! intervention. However, one should bear in mind the general limitations of an accelerometer. One of the strengths of the intervention is that it starts with a personal premeasurement. To estimate energy expenditure with the MOX, the MOX should be validated with DLW or indirect calorimetry. The effects on physical activity of the It's LiFe! tool embedded in primary care practice will be evaluated in a randomized controlled trial in 24 general practices.

\section{Acknowledgments}

We would like to thank all the participants. The It's LiFe! tool is a co-creation of the researchers, the engineering department of the faculty of Health Medicine and Life Science of Maastricht University (IDEE), and the following companies: Maastricht Instruments BV (Maastricht, The Netherlands) and Sananet Care BV (Sittard, The Netherlands). The researchers bought the tool from the companies and have no competing financial interests. This study was funded by The Netherlands Organization for Health Research and Development (ZonMW).

\section{Disclosure Statement}

No competing financial interests exist.

S.v.d.W. collected the data, carried out the initial analyses, and drafted the initial manuscript. H.E. processed the raw data and carried out the analysis for threshold definition. M.S. provided statistical advice and guidance and contributed to manuscript drafting. R.V. and H.T. contributed to manuscript drafting. L.d.W. initiated the initial It's LiFe! study and contributed to manuscript drafting. K.M. formulated the research questions and supervised data collection, analyses and manuscript preparation. All authors critically reviewed the manuscript and approved the final manuscript as submitted. 


\section{VAN DER WEEGEN ET AL.}

\section{REFERENCES}

1. Murphy SL. Review of physical activity measurement using accelerometers in older adults: Considerations for research design and conduct. Prev Med 2009;48:108-114

2. Warburton $\mathrm{DE}, \mathrm{Nicol} C \mathrm{CW}$, Bredin SS. Health benefits of physical activity: The evidence. CMAJ 2006;174:801-809.

3. Physical inactivity: A global public health problem. Global strategy on diet, physical activity and health. Geneva: World Health Organization, 2013.

4. Orrow G, Kinmonth A-L, Sanderson S, Sutton S. Effectiveness of physical activity promotion based in primary care: Systematic review and meta-analysis of randomised controlled trials. BMJ 2012;344:e1389.

5. Avery L, Flynn D, van Wersch A, Sniehotta FF, Trenell MI. Changing physical activity behavior in type 2 diabetes: A systematic review and meta-analysis of behavioral interventions. Diabetes Care 2012;35:2681-2689.

6. van Achterberg T, Huisman-de Waal GG, Ketelaar NA, Oostendorp RA, Jacobs JE, Wollersheim HC. How to promote healthy behaviours in patients? An overview of evidence for behaviour change techniques. Health Promot Int 2011;26:148-162.

7. Bravata DM, Smith-Spangler C, Sundaram V, et al. Using pedometers to increase physical activity and improve health: A systematic review. JAMA 2007;298:2296-2304.

8. Plasqui G, Westerterp KR. Physical activity assessment with accelerometers: An evaluation against doubly labeled water. Obesity (Silver Spring) 2007;15:2371-2379

9. van der Weegen $S$, Verwey $R$, Spreeuwenberg $M$, Tange $H$, van der Weijden $T$, de Witte $L$. The development of a mobile monitoring and feedback tool to stimulate physical activity of people with a chronic disease in primary care: A usercentered design. JMIR mHealth uHealth 2013;1:e8.

10. van der Weegen S, Verwey R, Tange HJ, Spreeuwenberg MD, de Witte LP. Usability testing of a monitoring and feedback tool to stimulate physical activity. Patient Prefer Adherence 2014;8:311-322.

11. Verwey $R$, van der Weegen $S$, Spreeuwenberg $M$, Tange $H$, van der Weijden T and de Witte L. A pilot study of a tool to stimulate physical activity in patients with COPD or type 2 diabetes in primary care. J Telemed Telecare 2014;20:29-34.

12. Verwey $R$, van der Weegen $S$, Tange $H$, Spreeuwenberg $M$, van der Weijden $T$, de Witte L. Get moving: The practice nurse is watching you! A case study of the user-centred design process and testing of a web-based coaching system to stimulate the physical activity of chronically ill patients in primary care. Inform Primary Care 2012;20:289-298.

13. Hanggi JM, Phillips LR, Rowlands AV. Validation of the GT3X ActiGraph in children and comparison with the GT1M ActiGraph. J Sci Med Sport 2013;16:40-44.

14. Sasaki JE, John D, Freedson PS. Validation and comparison of ActiGraph activity monitors. J Sci Med Sport 2011;14:411-416.

15. Vanhelst J, Mikulovic J, Bui-Xuan G, et al. Comparison of two ActiGraph accelerometer generations in the assessment of physical activity in free living conditions. BMC Res Notes 2012;5:187.

16. Van Remoortel H, Raste $Y$, Louvaris $Z$, et al. Validity of six activity monitors in chronic obstructive pulmonary disease: A comparison with indirect calorimetry. PLoS One 2012;7:e39198.

17. Rabinovich RA, Louvaris $Z$, Raste $Y$, et al. Validity of physical activity monitors during daily life in patients with COPD. Eur Respir J 2013;42:1205-1215.
18. Annegarn J, Spruit MA, Savelberg HH, et al. Differences in walking pattern during 6-min walk test between patients with COPD and healthy subjects. PloS One 2012;7:e37329.

19. Bouten CV, Koekkoek KT, Verduin M, Kodde R, Janssen JD. A triaxial accelerometer and portable data processing unit for the assessment of daily physical activity. IEEE Trans Biomed Eng 1997;44:136-147.

20. Preece SJ, Goulermas JY, Kenney LP, Howard D, Meijer K, Crompton R. Activity identification using body-mounted sensors-A review of classification techniques. Physiol Meas 2009;30:R1.

21. van Hees VT, van Lummel RC, Westerterp KR. Estimating activity-related energy expenditure under sedentary conditions using a tri-axial seismic accelerometer. Obesity (Silver Spring) 2009;17:1287-1292.

22. Esliger DW, Rowlands AV, Hurst TL, Catt M, Murray P, Eston RG. Validation of the GENEA accelerometer. Med Sci Sports Exerc 2011;43:1085-1093.

23. Dowd KP, Harrington DM, Donnelly AE. Criterion and concurrent validity of the activPAL professional physical activity monitor in adolescent females. PLoS One 2012;7:e47633.

24. Kaminsky LA, Ozemek C. A comparison of the Actigraph GT1M and GT3X accelerometers under standardized and free-living conditions. Physiol Meas 2012;33:1869-1876.

25. Vanhelst J, Hurdiel R, Mikulovic J, et al. Validation of the Vivago wrist-worn accelerometer in the assessment of physical activity. BMC Public Health 2012;12:690

26. Trost SG, Way R, Okely AD. Predictive validity of three ActiGraph energy expenditure equations for children. Med Sci Sports Exerc 2006;38:380-387.

27. Santos-Lozano A, Santin-Medeiros F, Cardon G, et al. Actigraph GT3X: Validation and determination of physical activity intensity cut points. Int J Sports Med 2013;34:975-982.

28. Hendelman D, Miller $\mathrm{K}$, Baggett $\mathrm{C}$, et al. Validity of accelerometry for the assessment of moderate intensity physical activity in the field. Med Sci Sports Exerc 2000;32(9 Suppl):S442-S449.

29. Baarends EM, Schols AM, Pannemans DL, et al. Total free living energy expenditure in patients with severe chronic obstructive pulmonary disease. Am J Respir Crit Care Med 1997;155:549-554.

30. Choquette S, Hamel M, Boissy P. Accelerometer-based wireless body area network to estimate intensity of therapy in post-acute rehabilitation. $J$ Neuroeng Rehabil 2008;5:20.

Address correspondence to:

Sanne van der Weegen, MSc

CAPHRI School for Public Health and Primary Care

Maastricht University P.O. Box 616

6200 MD, Maastricht The Netherlands

E-mail: s.vanderweegen@maastrichtuniversity.nl

Received: May 13, 2014

Revised: June 23, 2014

Accepted: June 26, 2014 